\title{
Is COVID-19 anticipating the future? Evidence from investors' sustainable orientation
}

\author{
Rocco Caferra $^{1,2} \cdot$ Pasquale Marcello Falcone ${ }^{3} \cdot$ Andrea Morone $^{1}$. \\ Piergiuseppe Morone ${ }^{4}$ (i)
}

Received: 22 July 2021 / Revised: 27 October 2021 / Accepted: 30 December 2021 /

Published online: 22 February 2022

(c) The Author(s) under exclusive licence to Eurasia Business and Economics Society 2022

\begin{abstract}
In this paper, we discuss the attractiveness of green and sustainable assets, from an investor perspective. Inspired by the current state of the art, with researchers positively (re)considering the added value of stocks associated with the fulfilment of sustainable development goals, we analyze whether such stocks demonstrated: (1) a different and (2) an outperforming dynamic during various stages of the COVID-19 pandemic. In particular, we examine sustainable-indexed assets and companies with a fully bio-based production system, against a counterfactual group of non-indexed activities operating in the same sectors. Asset connectivity is investigated by means of a correlation network, and portfolio optimization is applied to measure profitability. The results show: (1) fewer connections between bio-based assets and the "rest of the world," suggesting that, given their potential long-term resilience, investors might consider them capable of mitigating COVID-19 systemic risk, and therefore a valid investment to hold; and (2) the effectiveness and profitability of bio-based assets in portfolios. Considering the latter finding, we document a switching effect after the hard lockdown phase, during which rational investors (seeking an optimal mean-variance) may have inferred the efficacy of capital re-allocation from simply sustainable assets to bio-based companies. Here, we discuss the potential role of the pandemic as an accelerator of the sustainable green transition, considering the welfare implications in terms of socio-economic wellbeing and reduction of negative environmental externalities deriving from the conversion of the traditional production and management system. The profitability of the returns investments might increase the attractiveness of sustainable management organizations, causing the diffusion of these virtuous systems to increase further.
\end{abstract}

Keywords COVID-19 $\cdot$ Sustainable assets $\cdot$ Bio-based $\cdot$ Network analysis $\cdot$ Portfolio optimization

Piergiuseppe Morone

piergiuseppe.morone@unitelmasapienza.it

Extended author information available on the last page of the article 


\section{JEL Classification Q56 · G11}

\section{Introduction}

The idea that the "future is green and sustainable" is pervading our thoughts, directing our economic plans and refashioning our lifestyles (da Graça Carvalho, 2012; Smith, 2010). There is broad consensus among international institutions and governments that global economic reliance on fossil fuels must be scaled down, in order to effect a more responsible and resource efficient society. This need for change is even more evident in the post-COVID-19 era. Indeed, the near global lockdown in response to the COVID-19 pandemic represented an extraordinary disruption for economies, bringing about significant shocks to both demand and supply. On the one hand, non-essential household spending significantly contracted; on the other hand, entire industries shut down, leading to a rise in unemployment.

The COVID-19 outbreak, followed by an unprecedented economic and financial market collapse and the deterioration of the global production system, seriously undermined any assumptions about the correct state of the world. As a result, proposals for a faster, more resilient, green and sustainable economy re-emerged (Lahcen et al., 2020). Recently, researchers have examined the financial implications of the initial phase of COVID-19: Döttling and Kim (2020) showed how funds with the highest sustainability ratings experienced sharper declines in flow, while Chiappini et al. (2021) found that sustainable and non-sustainable assets performed a similar bear phase. Some positive insights emerged from Selmi et al. (2021), who demonstrated an interesting positive linkage between COVID-related anxiety and an acceleration in sustainable investments. These results suggest that "charting the green path" after the pandemic may be a non-trivial task (Mukanjari \& Sterner, 2020), and that more efforts are needed to shed light on the attractiveness of such investments to support a sustainable future.

At the time of writing (July 2021), the COVID-19 pandemic has been impacting lives for more than 1 year. It is therefore worth examining whether radical changes in the overall perception of sustainable investments have occurred over this time. More specifically, our research aimed at examining the profitability of investments in "green and sustainable" assets.

Here, several points must be clarified. To effectively compare the value of green sustainable assets in a portfolio, we constructed a sample equally composed of: (1) sustainable assets (drawing from well-known indexes, such as the Dow Jones and the EURO STOXX Sustainability Index), (2) conventional counterparts with similar characteristics (according to, e.g., geographic area, market sector and relevance) and (3) a subset of assets related to fully bio-based companies. In this way, we sought to measure whether the optimal share of sustainable assets in a portfolio increased (decreased) over time, relative to a proper counterfactual.

Considering the first point of the analysis, we constructed an asset correlation network to identify potential connections among sustainable/non-sustainable assets (Wang et al., 2019). This allowed us to compare the dynamics of the different financial activities, and therefore to evaluate the extent to which COVID-19 collapsed the 
system. Where no differences in dynamics and interconnectedness were detected, we concluded that there was no "resilience effect" for green assets and, more generally, no perceived differences from the investor perspective, as such assets could be evaluated as equivalent to non-sustainable assets. Conversely, where fewer connections were found in one category, we concluded that shareholders evaluated investments in these assets differently. For instance, as will be empirically discussed in Sect. 4, investors might have considered bio-based stocks to have the largest future perspectives, and thus the highest future expected value. This would make these assets less anchored to short- and medium-run negative sentiments and shocks (e.g. COVID19), and lead to a partial detachment from the rest of the market.

Considering the second aspect of the analysis, we applied portfolio optimization to capture the dynamics of the sustainable assets compared with the counterfactual, and thereby to evaluate their profitability in a portfolio. We expected to uncover a possible "anticipation" of long-run change, which might reduce the frailty of these assets and increase investors' trust in the green and sustainable revolution. From a portfolio perspective, this would be evident by an increased share of these assets, due to their high profitability and low volatility (i.e. less frailty). Our findings were thought to contribute to the development of an informed view about the resiliency of sustainable assets, as such assets are pivotal in the transition towards sustainability.

The remainder of the paper is organized as follows: Sect. 2 reviews the existing literature, Sect. 3 introduces a preliminary description of the data and outlines the methodology employed, Sect. 4 reports the results and Sect. 5 provides a concluding discussion.

\section{Literature and hypotheses}

There is a well-known strand of literature focusing on sustainable portfolio performance, emphasizing the integration of environmental, social and corporate governance considerations (i.e. socially responsible investments; SRI) within the investment process (Capelle-Blancard \& Monjon, 2012). Responsible investors are moved by personal value systems and beliefs about both financial and non-financial utilities (Benson \& Humphrey, 2008). In this vein, the theoretical literature acknowledges different visions about the profitability of sustainable investment choices, as held by opponents, supporters and neutral parties (Auer, 2016). The opponent perspective commonly contends that sustainable investments decrease investment prospects (Renneboog et al., 2008) and raise screening costs (Clacher \& Hagendorff, 2012). The neutral vision highlights that, as sustainability is not valued from a financial perspective, sustainable investments are equivalent to their convectional counterparts in terms of risk-return (Humphrey et al., 2012). Finally, the supporting viewpoint (which is spreading) asserts that sustainable investors might benefit from firms' "good reputation and sustainable competitive advantage" (Wu et al., 2017), even during market shocks (Nofsinger \& Varma, 2014).

In the empirical literature, two main emphases emerge. First, studies have mostly analyzed the sustainable portfolio performance of a few sustainable indexes (Cunha et al., 2020), with a vast majority considering only one index and 
its market peer (Collison et al., 2008; Consolandi et al., 2009), and only a few studies building upon different indexes (Managi et al., 2012; Ur Rehman et al., 2016). Second, while there have been numerous studies on whether investors in sustainable funds pay a price for these investments or obtain greater returns, only very few empirical studies have addressed the performance of sustainable investments during market downturns, and many of these have been inconclusive (Leite $\&$ Cortez, 2014). Generally speaking, the literature is concentrated on sustainable indexes and the global investigation of sustainable portfolio performance, offering contradictory results. In particular, Wu et al. (2017) examined a full economic circle-from economic boom through to recession and recovery-from 2004 to 2011 (including the 2007-2009 financial crisis), comparing the performance of two value-weighted investment portfolios: FTSE4Good (SRI portfolio) and FTSE 350 (conventional portfolio). They found that the SRI portfolio performed better and recovered its value quicker in the post-crisis era, relative to the conventional portfolio. Lean and Pizzutilo (2020) investigated the MSCI SRI index in different markets (i.e. North America, Europe, Asia Pacific and Japan), showing that the performance of sustainable indexes did not significantly differ from that of their family peers, even during the global financial crisis. Nofsinger and Varma (2014) inspected the performance of a group of US SRI funds during crisis and non-crisis periods, over the years 2000-2011, demonstrating that conventional funds outperformed SRI funds in non-crisis times, while the reverse was true during crisis periods. Other analyses have acknowledged non-statistically significant performance differences between sustainable and traditional funds during crisis periods (Leite and Cortez, 2015; Matallín-Sáez et al., 2016).

Recently, the COVID-19 pandemic has stimulated research on sustainable investments and market downturns; however, the conclusions of this research remain questionable (Chiappini et al., 2021). A distinctive aspect of the COVID19 crisis, different from prior financial crises (e.g. the great recession of 2008), is that it has had an exogenous and real-time effect on the economy, directly impacting macroeconomic variables (and thus company returns) through quarantines and lockdowns. Against this background, the literature reports different findings concerning the early phase of the pandemic. Döttling and Kim (2020) demonstrated that funds with higher sustainability ratings showed sharper decreases in retail flows, after controlling for fund characteristics. Broadstock et al. (2021), focusing on Chinese businesses, suggested that better environmental, social and corporate governance (ESG) factors lowered financial risk during the crisis; however, Folger-Laronde et al. (2020) did not verify any indemnity role played by higher ESG performance in the relationship between ETFs' financial returns and their Eco-fund ratings. Chiappini et al. (2021), focusing on Europe and the USA, found that sustainable indexes were negatively affected by lockdown ordersthough they did not report any statistically significant different atypical returns compared to traditional indexes. Selmi et al. (2021) examined whether increased anxiety over COVID-19 affected attitudes and behaviors with respect to environmentally and socially responsible investing. Using machine learning sentiment analysis, they found that increased uncertainty and worry during the emergency period did not distract investors' attention away from environmental and social 
issues, and firms that proactively engaged with responsible strategies towards environmental issues tended to be more reactive to sentiments related to the consequences of the pandemic.

Given the recent-and ongoing-diffusion of the COVID-19 pandemic, the present study sought to contribute to this line of research by emphasiing the relevance of economic distress in perceptions of the profitability of investing in "green and sustainable" assets. In addition to enriching the recent literature on COVID-19, the study also aimed at contributing to the current debate over the performance of sustainable investments, as follows:

First, the study aimed at evaluating the financial performance of sustainable investments in a time of extraordinary exogenous shock at a global scale, while also considering the effect of lockdown orders and related measures.

Second, although prior research has analyzed the relationship between sustainable performance and financial performance (Endrikat, 2016; Revelli and Viviani, 2015), only a few studies have inspected the performance of sustainable indexes during times of crisis_and specifically market recessions.

Third, by concentrating on several sustainable indexes and their conventional counterparts, the study aimed at effectively comparing the convenience of green sustainable assets in a portfolio, while also considering a subset of fully biobased companies, with production processes based on raw materials of biological origin (excluding those embedded in geological formations and/or fossilized).

Based on the abovementioned literature, we aimed at testing the potential role of the pandemic as an accelerator in the sustainable green transition. Our central argument was that investors may perceive green and sustainable assets as capable of mitigating COVID-19 systemic risk and as secure investments, due to their future expected value. We expected these hedging properties to be reflected in the different dynamics and superior performance of the two classes of sustainable assets. We further considered that this gap would become more evident when moving from fossil-based to sustainable and bio-based sustainable industries. Therefore, we specified the following hypotheses:

H1 (Bio-based) sustainable assets would display fewer connections with the "rest of the world" during the COVID-19 lockdown. Briefly, we suspected that investors might perceive them as capable of mitigating COVID-19 systemic risk and as valid investments.

$\mathrm{H} 2$ (Bio-based) sustainable assets would be more resilient than traditional assets during the COVID-19 lockdown. In other words, we expected that investors would consider this type of asset demonstrative of future overperformance. This would also confirm H1, since the different dynamics would coincide with the overperforming pattern of sustainable assets.

To investigate these hypotheses concerning the impact of the COVID-19 shock, we focused on sustainable-indexed assets and companies with a fully biobased production system (as a proxy of deep sustainability involvement), with a 
counterfactual group of non-indexed activities operating in the same sectors. In the following section, we explain how we gathered the data, built the sample and applied the methodology.

H1 was analyzed by means of a network analysis, with correlation used as a proxy of connectivity between assets. We aimed at identifying whether all assets formed a unique connected financial world, or, conversely, whether different clusters of behavior emerged, in accordance with sustainable features. After observing the results of $\mathrm{H} 1$, we applied a portfolio optimization exercise to address $\mathrm{H} 2$.

\section{Data and methodology}

Before proceeding to describe the data analysis, we will first introduce the sample and the methodology employed, referring to the existing literature in the field.

\subsection{Sample selection}

The case study considered the time period 31/05/2019 to $31 / 12 / 2020,{ }^{1}$ composed of 370 daily returns $\left(r_{t}\right)$, calculated ${ }^{2}$ as $r_{t}=\log \left(p_{t} / p_{t-1}\right)$, of 60 assets, ${ }^{3}$ and clustered on the basis of the different management/production systems. In particular, 20 assets were classified as bio-based, since their production systems were fully based on the usage of biomasses; 20 assets were classified as sustainable-indexed, since they belonged to well-known lists of sustainable assets (specifically, the Dow Jones Sustainability World Index (DJWSI) ${ }^{4}$ and the EUROSTOXX Sustainability Index ${ }^{5}$ ); and as residual, we considered a counterfactual group of 20 industries that were not included in the previously mentioned lists and for which scraping on an authoritative source (www.wikipedia.org) generated no indication of reward for their sustainable activity. To homogenize the sample, we considered only the energy and material sectors, which can be associated with (or assimilated within) the first three $(10,15$, 20) codes of the GICS classification. These three sectors highly represent the whole universe of bio-based companies, motivating the selection of the other counterfactual groups searching into the same categories. Hence, we include the 20 sustainable and non-sustainable assets (1) considering the same categories and (2) testing

\footnotetext{
1 The logic behind the time window selection was as follows: we wanted to consider a period (semester) that both preceded the arrival of COVID-19 and included the first stage of the economic recovery phase. We closed the period of investigation at the end of 2020, since the beginning of 2021 coincided with the initiation of a global vaccine campaign, with different timings all over the world (hence, from 2021 onwards, the extent to which COVID-19 affected economies was thought to more significantly vary across countries).

${ }^{2}$ Data were sourced from Yahoo Finance. The calculation of returns was based on the adjusted closing price.

${ }^{3}$ Hereafter, the internal validity of the results and the adequacy of the sample size will be reported by discussing the post-hoc power achieved, where statistical differences were detected.

${ }^{4}$ https://www.spglobal.com/spdji/en/indices/esg/dow-jones-sustainability-world-index/\#overview.

5 https://www.stoxx.com/index-details?symbol=SUTE.
} 
their representativeness of the related market dynamics (see the Annex A as proof). ${ }^{6}$ Additionally, to better isolate the "bio-based" or "sustainable" effect, we controlled for investors' attractiveness, as derived from the balance sheet. As is known, different weights of liability can negatively compromise the evolution of a firm's market price and then higher levels of debt discourage investors investment in a given company. To this extent, we controlled for the pre-pandemic debt-to-capitalize ratio, finding no differences between groups. ${ }^{7}$ To ensure a synchronicity of virus outbreak, we considered only European and US markets, where the financial contagion and relative economic consequences were nearly simultaneous (Caferra and Vidal-Tomás, 2021). Table 1 reports the results of the group subdivision, as well as some descriptive statistics, including the minimum return per stock, the maximum value and the return-to-risk ratio, calculated as the mean return over the standard deviation.

No statistical differences emerged in the minimum values, as all were registered during the worst initial period of COVID-19, which, as well documented (Caferra and Vidal-Tomás, 2021), began at the end of February 2020. However, interesting results were registered for the return-to-risk ratios and the maximum values (see Fig. 1).

As shown in Fig. 1, sustainable assets demonstrated the best return-to-risk ratio, ${ }^{8}$ immediately followed by bio-based companies; non-indexed assets reported the worst performance. Interestingly, bio-based companies reported the highest average maximum value of returns. ${ }^{9}$

\subsection{Asset correlation (threshold) network}

Generally, a network is a model of interrelated units (called "vertexes" or "nodes") that interact with each other via "links" or "edges." All of these aspects are included in a graph $\mathrm{G}=(\mathrm{V}, \mathrm{E})$, consisting of vertexes (nodes) $\mathrm{V}$ and edges (links) $\mathrm{E}$. The intensity of the connection between two vertexes is expressed using the weight (w), which may fall on a continuous scale (in the case of weighted networks) or be represented as a simple weight of $1(0)$ to indicate the presence (absence) of a connection. The financial world can be helpfully represented by an asset correlation network, in which each vertex represents an asset and the intensity of a connection between vertexes represents the correlation between each vertex's return $(\rho)$. Following the

\footnotetext{
6 The number of fully bio-based industries is highly representative of the bio-based population, since it is quite hard to find a relevant higher number of companies that have completely re-converted their production system. We are aware that 20 companies are few compared with the whole European and American universe of firms. However, we have decided to preserve the same number of assets for each group for consistency. Therefore, we show that the assets selected reflects the prevailing market dynamics captured by EUROSTOXX and DJI indexes.

7 Data were downloaded from investing.com, considering balance sheets at the end of 2019. The average (standard deviation) values were as follows, with no statistical differences between groups: bio-based $0.603(0.301)$, sustainable-indexed $0.578(0.123)$ and non-indexed $0.510(0.120)$.

8 Alpha $=0.054$; beta (probability of type II error) $=0.08$.

9 Alpha $=0.004$; beta (probability of type II error) $=0.12$.
} 
Table 1 Sample description

\begin{tabular}{|c|c|c|c|}
\hline Asset no. & Bio-based & Indexed & Non-indexed \\
\hline 1 & Avantium & ONEOK & Exxon Mobil \\
\hline 2 & BASF & Dow Inc & Chevron \\
\hline 3 & NextEra Energy & Newmont Corporation & AES \\
\hline 4 & Biome Technologies & Sempra Energy & Diamondback Energy, Inc \\
\hline 5 & Yield10 Bioscience & IMCD & Exelon \\
\hline 6 & CSM NV & UMICORE & VICTREX \\
\hline 7 & Evonik industries & STORA ENSO R & SIKA \\
\hline 8 & Neste Oil & LINDE & WEIR GRP \\
\hline 9 & Global Bioenergy & AIR LIQUIDE & TOTAL \\
\hline 10 & Novozymes & IBERDROLA & ENGIE \\
\hline 11 & Amyris & SAINT GOBAIN & $\begin{array}{l}\text { SCOTTISH AND } \\
\text { SOUTHERN ENERGY }\end{array}$ \\
\hline 12 & Enphase Energy & RWE & EQUINOR \\
\hline 13 & Renewable Energy Group & SIGNIFY & ARCELORMITTAL \\
\hline 14 & Maire Tecnimont & ENEL & BOLIDEN \\
\hline 15 & Clariant & KINGSPAN GRP & NIBE INDUSTRIER \\
\hline 16 & Novisource & BOUYGUES & SKF \\
\hline 17 & Borregaard & COVESTRO & EVRAZ \\
\hline 18 & Eaton Corporation & SNAM RETE GAS & ARKEMA \\
\hline 19 & Solvay Group & $\mathrm{CRH}$ & ANTOFAGASTA PLC \\
\hline 20 & FutureFuel Corporation & $\mathrm{A} 2 \mathrm{~A}$ & $\mathrm{BP}$ \\
\hline Minimum & $-0.190(0.137)$ & $-0.177(0.081)$ & $-0.189(0.103)$ \\
\hline Return-to-risk & $0.030(0.041)$ & $0.033(0.024)$ & $0.015(0.039)$ \\
\hline Maximum & $0.213(0.123)$ & $0.119(0.527)$ & $0.147(0.042)$ \\
\hline
\end{tabular}

winner-takes-all approach (Vidal-Tomás, 2021), a threshold ( $\theta$ ) may be applied to identify the existence of a link, with the weight of the link equivalent to 0 when the pairwise correlation is lower than the threshold $(\rho<\theta)$ (or $w=\rho$ in the opposite case $(\rho>\theta))$.

Previous studies have applied this approach to gain insight into diversification strategies to reduce unsystematic risk (for a recent review of this topic, see Wang et al., 2019), looking for assets or groups of assets that are poorly connected with the main network (i.e. the prevailing market dynamics). Some applications can be found in the energy sector to calculate related financial risk (Restrepo et al., 2018) and the connectedness of the traditional and renewable energy sector (Zheng et al., 2021); in a similar vein, Herskovic (2018) and Majapa and Gossel (2016) examined the production sectors.

Inspired by the abovementioned studies, we considered different network measures to capture overall network connectivity and the level of connection between each vertex and the network, in both an unweighted and a weighted version. In particular, we considered the following metrics: 


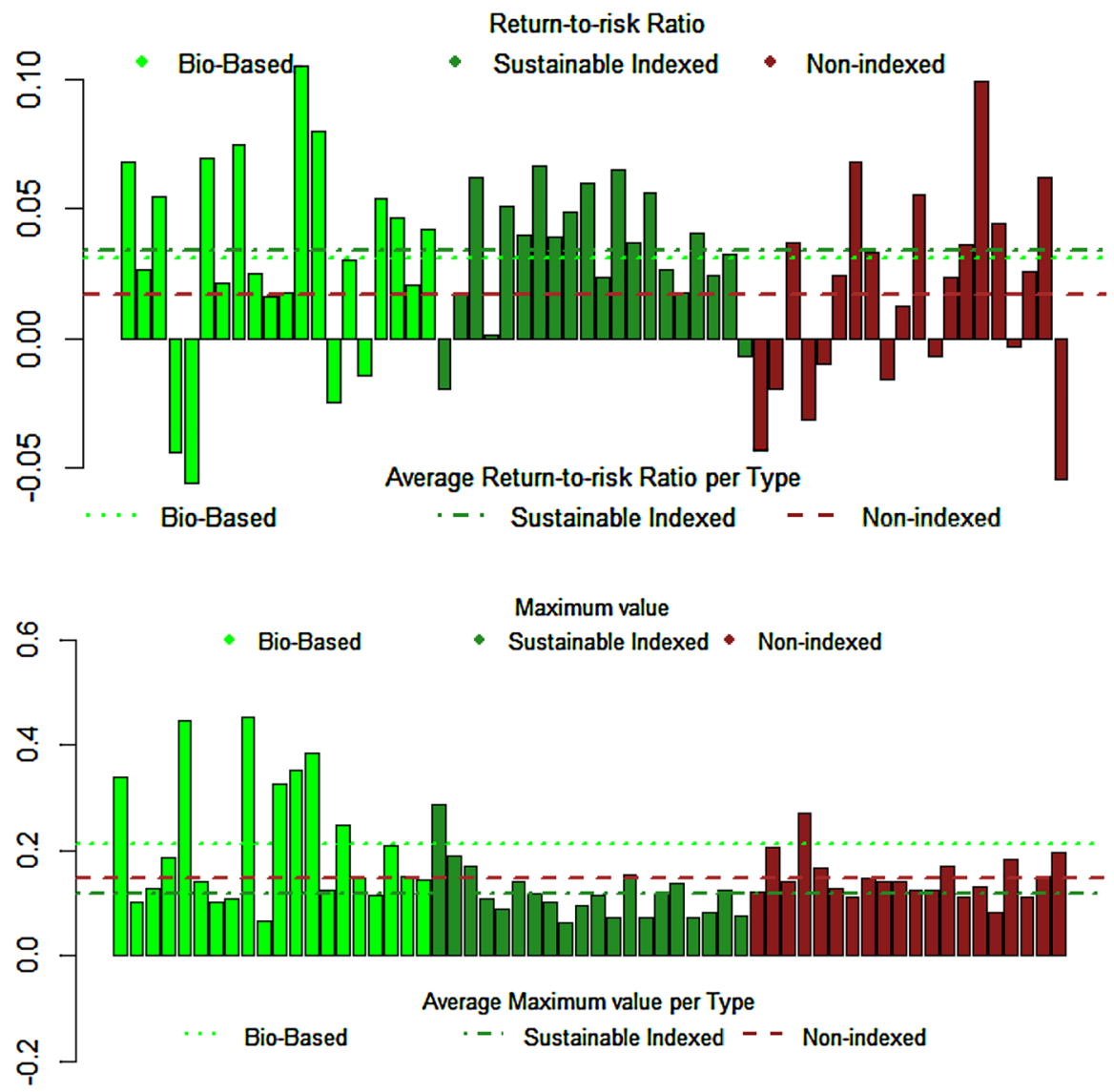

Fig. 1 Descriptive statistics: return-to-risk (above) and maximum value per asset (below)

Network density Network density is measured by the ratio between actual to potential connections. Given that each of $n$ vertexes might link with the remaining $\mathrm{n}-1$, and that the order of the link does not matter, the theoretical maximum density is $n(n-1) / 2$. Actual connections are represented by the empirical number of links observed. The normalized value varies from 0 (representing a totally disconnected network) to 1 (representing a fully connected network).

Vertex degree centrality Vertex degree centrality refers to the number of edges attached to a vertex. This value can be normalized by the maximum number of nodes, or $\mathrm{n}-1$, where $\mathrm{n}$ is the number of vertexes. As before, this metric varies from 0 to 1 .

Vertex strength Vertex strength in a weighted network is represented by the sum of the weights of the vertex's adjacent edges. Therefore, differently from vertex degree centrality, in vertex strength, links are weighted in accordance with the size of the correlation. 
We expected to observe an increase in general network density during the hard lockdown, since this shock affected the entire production system. Regarding vertex measures, we expected that degree centrality and strength (i.e. connectivity with market dynamics) would vary in accordance with the type of investment. In particular, we expected to observe less connectivity with bio-based and/or sustainable assets, on the assumption that investors might have perceived these assets as "detached", with higher future values (given their contribution to sustainable development goals); this, in turn, would be reflected in the assets' separate and different dynamics.

\subsection{Portfolio optimization}

Markowitz's mean-variance analysis is the milestone of modern portfolio theory (Luenberger, 1997; Markowitz, 1952). The technique aims at finding the optimal weight (i.e. the optimal capital allocation among assets) to ensure that the overall portfolio provides the least risk for a given return target. In the process, the so-called "efficient frontier" is outlined for each expected return, as is the tangency portfolio - that is, the portfolio that reflects the allocation whereby the cost of assuming extra risk (i.e. increased variance) is not compensated by a more than proportional increase in return (i.e., the portfolio maximization of the Sharpe ratio ${ }^{10}$; Sharpe, 1963). With a particular focus on the environment and resource economics, this approach has been used to explore the convenience of importing in specific oil sectors (Bigerna et al., 2021) and the efficiency of the wind energy system (SantosAlamillos et al., 2017). Some positive insights emerged from Bhattacharya and Kojima (2012), who found a risk reduction from the inclusion of renewable energy investment classes in a portfolio. More theoretical research has also demonstrated that sustainable investments can be profitable in a portfolio (Qi \& Li, 2020), and that the added value of these investments, linked to their contribution to the fulfillment of sustainable development goals, might be crucial in post-COVID-19 portfolio (re) construction (Yoshino et al., 2021). However, empirical support for these findings are lacking, and more efforts are needed along this direction.

The main expectation of the present study was the overperformance of bio-based and/or sustainable assets compared with the counterfactual group.

To this end, we have conducted two distinct portfolio optimization exercises: (1) in the first one, we have considered the whole sample composed by the selected 60 firms (i.e. sustainable indexed, non-indexed and bio-based), while (2) in the second one, we have performed the same analysis considering three representative assets, where each of them is composed by the daily cross-sectional average of the returns belonging to a specific subsample.

\footnotetext{
${ }^{10}$ For simplicity, we considered 0 a risk-free rate investment, coming ahead with the simple mean-variance maximization.
} 


\section{Results}

In the study, we employed the iterative cumulative sum of squares (ICSS) algorithm to identify breaks in the volatility of returns. Following this, we split the sample into periods that reflected statistically different return features. The ICSS algorithm, developed by Inclan and Tiao (1994), can be useful for detecting structural breakpoints according to variance in time series data. Prior research has applied it to split samples on the basis of different time series regimes (Gebka and Wohar, 2013). In the present study, ICSS was useful for identifying three timeframes, characterizing different phases of the COVID-19 outbreak: (1) from the beginning to 24/02/2020 (167 observations per time series; the pre-pandemic/early pandemic phase), (2) from $25 / 02 / 2020$ to $25 / 06 / 2020$ (77 observations per time series; the period of hard lockdown and severe stringency measures) and (3) 26/06/2020 to 29/31/2020 (126 observations per time series; the beginning of the recovery, after the first phase of virus spread). By considering these distinct timeframes, we were able to explore the market evolution across different stages of the pandemic.

In what follows, we report the results of our analyses, considering the full sample. First, we introduce the results of the correlation network, comparing the different dynamics; and second, we discuss the prominent role played by bio-based and sustainable assets in investment portfolios.

\subsection{Asset correlation (threshold) network}

Figure 2 reports the network configuration across the three phases. We considered as threshold $(\theta)$ the average market correlation calculated for the entire period, which was rounded up to $\theta=0.40$. Interestingly, the network became denser during the pandemic and less dense following the lockdown. In this latter phase, bio-based companies exhibited a separate dynamic: several nodes were totally disconnected, while others were connected on the periphery, as evidenced by their distance from the dense central core. The findings that emerged from a visual inspection of the network were supported by the data, as the normalized network density was 0.220 in the pre-pandemic phase, 0.709 during the lockdown and 0.203 in the early recovery period, returning to the initial value. To more deeply investigate the different dynamics of bio-based companies, we estimated vertex centrality (Fig. 3) and vertex strength (Fig. 4).

Figure 3 displays the normalized vertex degree centralities, on a range of 0 (in the case of a totally disconnected network) to 1 (in the case of a fully connected network). As is evident, bio-based companies were poorly connected with the rest of the network, ${ }^{11}$ marked by different dynamics. Indeed, they were mostly disconnected

\footnotetext{
11 All differences between bio-based and other asset classes were statistically significant at all levels (following the t-test). Power tests revealed a beta (type II error) approaching 0.
} 


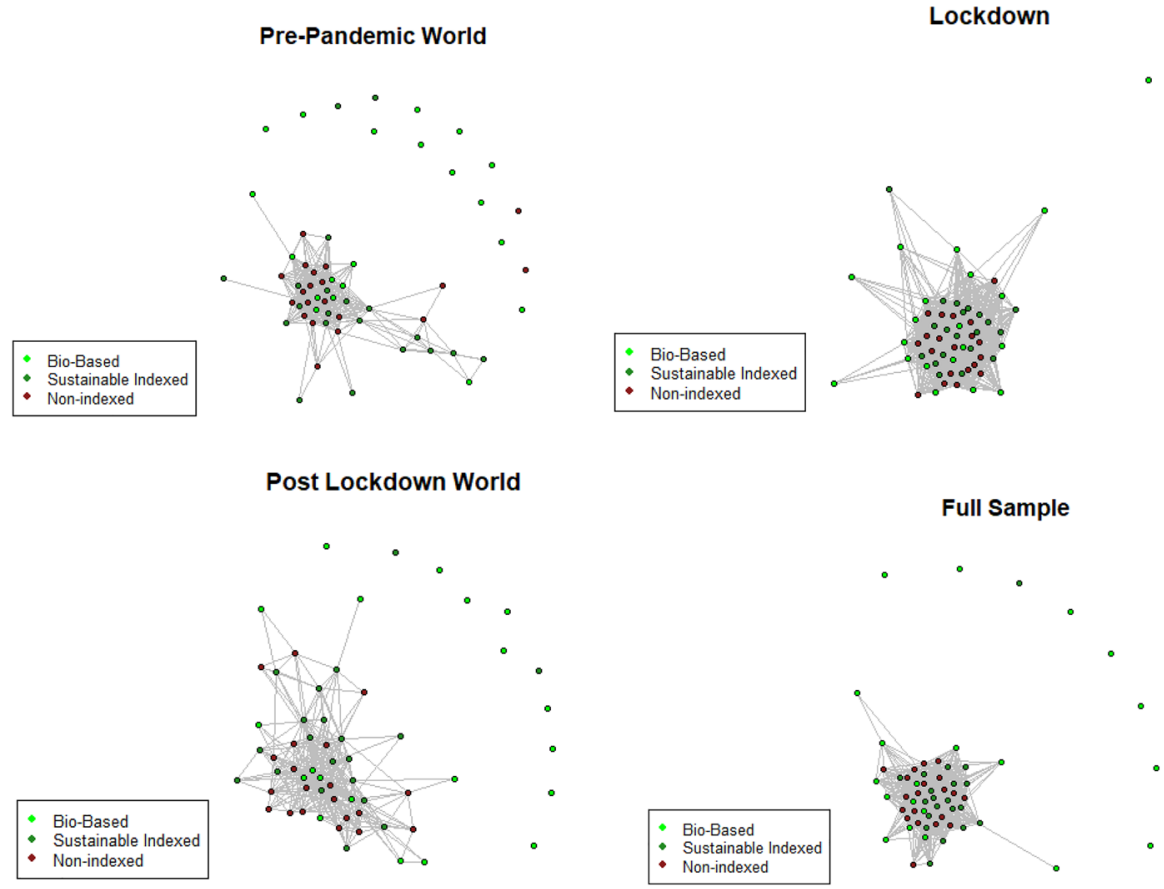

Fig. 2 Network configurations across COVID-19 phases
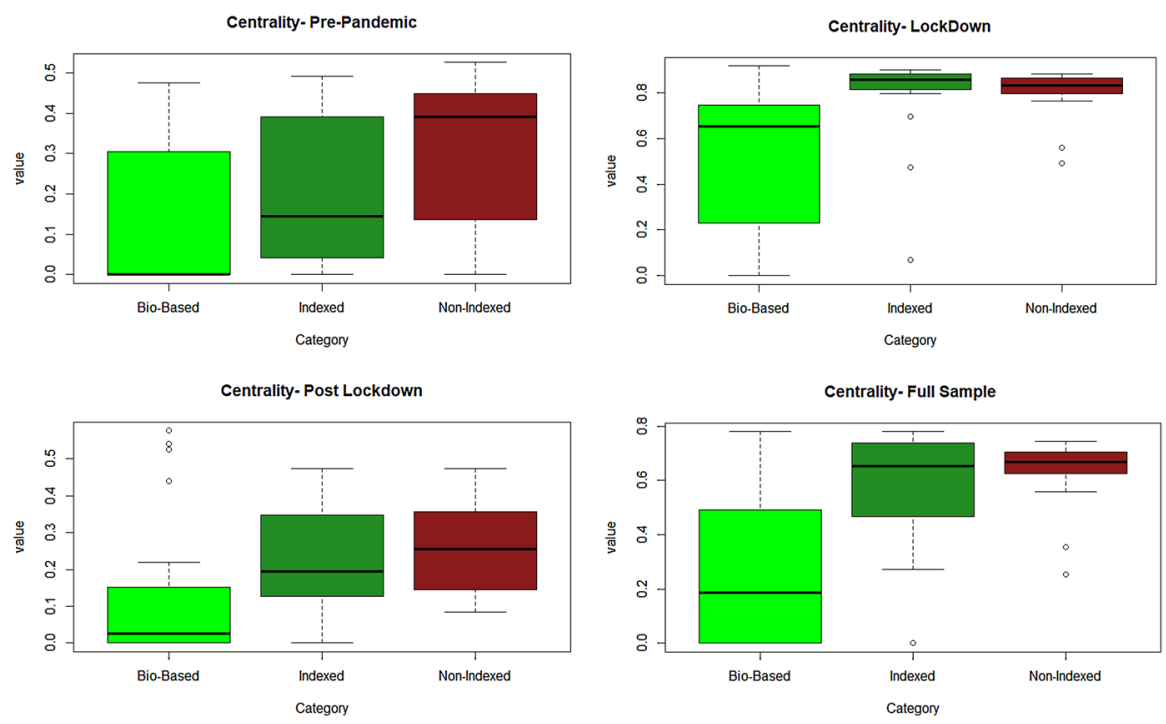

Fig. 3 Vertex degree centrality across COVID-19 phases 

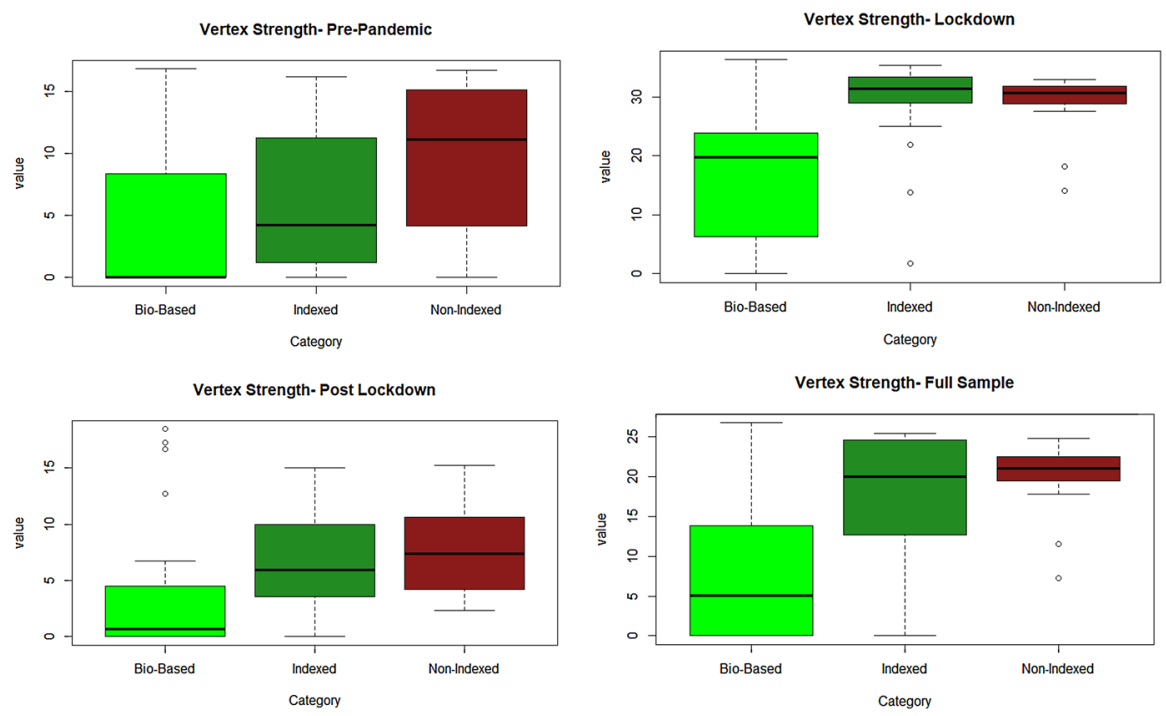

Fig. 4 Vertex Strength centrality across COVID-19 phases

or peripheral (i.e. outside of the densely connected core). Interestingly, this disconnection became more marked during the COVID-19 outbreak.

Figure 4 displays the weighted measures of connection. The results were identical to those of the previous exercise, reporting the same statistical significance.

Different from the research conducted by Zheng et al. (2021), which found homogeneous risk diffusion in the Chinese energy market from 2012 to 2020, due to interconnectedness even in renewable source markets, the present research found low interconnection, even during the drastic event of COVID-19.

The analysis underlined the different dynamics of bio-based enterprises: while there was a connection between sustainable indexed approaches and non-indexed approaches during the pandemic, companies that fully exploited biomasses in their production (i.e. companies that employed techniques representing the future expectations of a global sustainable production system) demonstrated a different pattern. A possible financeoriented explanation for this difference may pertain to shareholder perceptions of these financial activities: shareholders are likely to diversify their portfolio with instruments they perceive to offer the largest future perspectives and, subsequently, the highest future expected values. Such assets are likely to be less susceptible to short- and medium-run negative sentiments and shocks (e.g. COVID-19), and thus partially detached from the rest of the market. However, if this theory were to be borne out, the assets would not only show a different dynamic, but they would also be considered more attractive investments. This point will be discussed in the following analysis.

\subsection{Tangency portfolio}

Figure 5 presents the results of the portfolio optimization. As discussed in Sect. 3, the weights identify the precise allocation of capital to ensure an optimal 
Tangency Portfolio Composition- Pre Covid

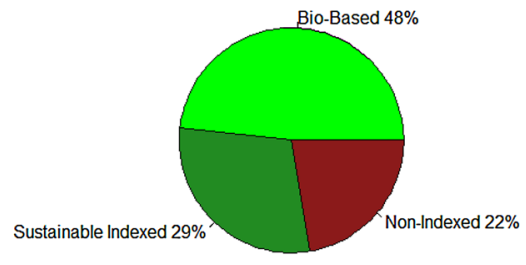

Tangency Portfolio Composition-Post Lockdown

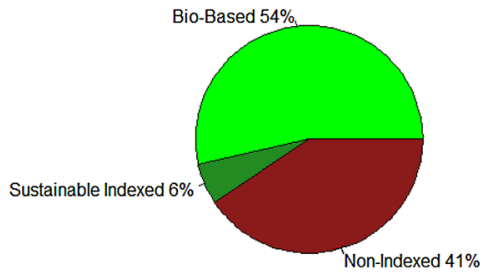

Tangency Portfolio Composition-Lockdown

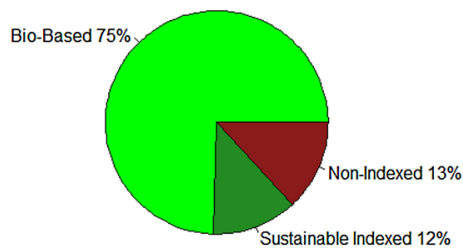

Tangency Portfolio Composition-Full Sample

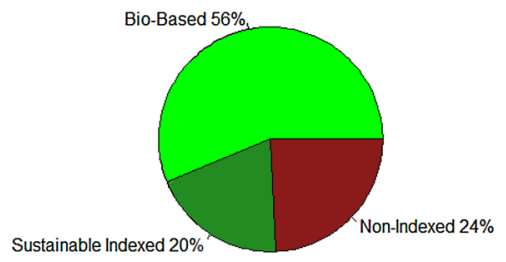

Fig. 5 Optimal portfolio across COVID-19 phases

mean-variance trade-off. As is evident, bio-based industries were predominant throughout COVID-19, while the share of sustainable assets diminished.

This result became even more evident during the second step of the analysis, which considered the entire sample (i.e. 60 assets). As further proof, we reduced heterogeneity by considering a "representative asset" of each category. In this way, we generated an aggregate measure of bio-based, indexed and non-indexed companies, composed of the daily cross-sectional average return of the 20 assets of each category (as described in Sect. 3.3). Figure 6 presents the results, showing a switch from sustainable-indexed to fully bio-based companies, indicated by an overturning of the optimal share during COVID-19.

This analysis validated the results of the asset correlation network analysis, discussed above. From a finance-oriented perspective, the different expectations of investors may reverberate in actual factors of greater attractiveness. Indeed, at the advent of COVID-19, a capital allocation that favored bio-based assets was perceived as most attractive and convenient. Therefore, it could also be considered a solution for mitigating systemic risk. 

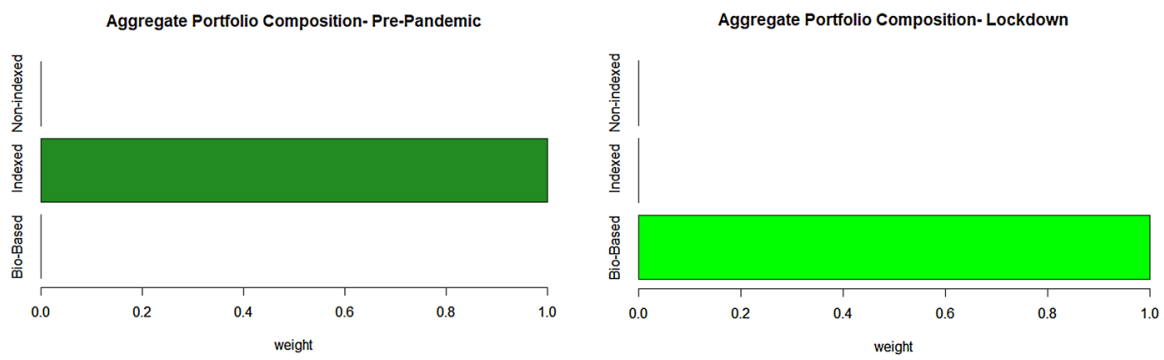

Aggregate Portfolio Composition- Post-Lockdown
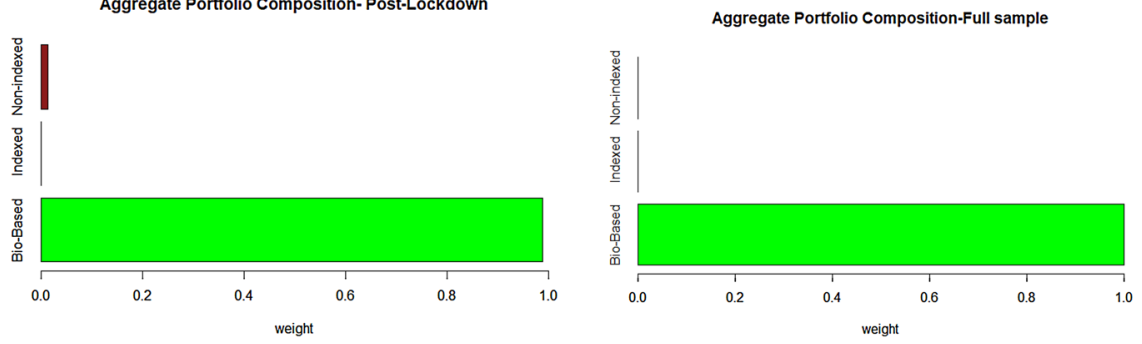

Fig. 6 Optimal portfolio across COVID-19 phases, considering the average daily return of the 20 assets in each category

\section{Conclusions and implications}

The present analysis adds to the literature on the stock market response to economic downturns (Ashraf, 2020; Nofsinger and Varma, 2014; and Wu et al., 2017), concentrating on the sustainability market and the less-explored fields of sustainable indexes and the COVID-19 pandemic (Chiappini et al., 2021; Döttling \& Kim, 2020; Selmi et al., 2021).

Focusing on sustainable-indexed assets, including both traditional and bio-based firms (as a proxy for deeper involvement in sustainability), and considering also a counterfactual group of non-sustainable indexed activities in the same sectors, we investigated the potential role of the COVID-19 outbreak as a catalyzer of the transition towards sustainability.

Specifically, to test our research hypotheses, we employed an asset correlation network to understand the potential connections between sustainable and non-sustainable assets, and applied portfolio optimization to examine the dynamics of sustainable assets with respect to traditional assets, in terms of profitability.

Our analyses found: (1) fewer connections between bio-based assets and the "rest of the world", possibly because investigators predicted that bio-based assets would not only mitigate COVID-19 system risk, but also represent a secure investment (given their potential long-run resilience and future expected value); and (2) a high level of profitability derived from the inclusion of bio-based assets in investment portfolios. These findings were made robust through the application of multiple network measures (i.e. vertex strength and degree centrality) and analyses of asset 
composition (considering both the set of specific assets and average values for each asset category).

The detection of a relevant difference between sustainable and traditional indexes during COVID-19 has significant practical implications. Financial-oriented investors might select sustainable investments to differentiate their portfolio and be less anchored to short- and medium-run negative effects and shocks (e.g. COVID-19). Accordingly, ceteris paribus, investment in sustainable assets may be preferable due to the higher "resilience effect" of these assets in the market, and thus their ability to foster a faster economic recovery. Therefore, our findings recognize the important role played by "sustainability" and predict an increased market share of biobased products and investments associated with sustainable production. However, some issues related to the ESG screening procedures of sustainable indexes (Birindelli and Chiappini, 2021; Escrig-Olmedo et al., 2019) require policy measures and actions to remedy. The establishment of national working groups and authoritative bodies aimed at investigating and determining optimal ways of integrating sustainability principles into the assessment of bio-based corporate performance along the entire supply chain is paramount. This would foster a trustworthy market of ESG investments within the bio-based industry, and ensure market growth.

Some limitations of the present study must be recognized. First, the consideration of a single-although highly relevant - event (i.e. the COVID-19 pandemic) limits the generalizability of the results. Second, the selection of a limited number of assets did not allow us to comprehensively examine the specificities of the pandemic, although the sample selection was sufficient to identify the main trends. Since the adopted procedure successfully defines the market dynamics, one suggestion might be to replicate the same approach by employing (1) different samples and (2) different categories (e.g. financial and communication services, information technology, etc.). This will offer a broader understanding of the global financial landscape across the different stages of the virus outbreak. Further research in this area would be valuable and timely. Additionally, future studies might extend the study sample and investigate the long-term performance of sustainable assets over a larger pandemic period.

\section{Appendix A}

In the following Table 2 we report the correlation of each sustainable indexed/ non-indexed company with the reference market index and the related t-test on the returns distribution. Specifically, we consider the Eurostoxx Sustainability Index and the Dow Jones world Sustainability index as references for the sustainable category, while the traditional Eurostoxx and Dow Jones are employed for those companies that are not indexed in a sustainable benchmark. The high and positive correlation combined with the non-statistically different distribution of returns confirm the representativeness of our sample. 
Table 2 Pairwise Correlation test and t-test on returns between each company and the reference indices

\begin{tabular}{|c|c|c|c|c|c|c|}
\hline \multirow[t]{2}{*}{ Asset no. } & \multirow[t]{2}{*}{ Category } & \multirow[t]{2}{*}{ Company } & \multicolumn{2}{|c|}{$\begin{array}{l}\text { Correlation with the refer- } \\
\text { ence index }\end{array}$} & \multicolumn{2}{|c|}{$\begin{array}{l}\mathrm{T} \text {-Test ( } \mathrm{p} \text {-value) on } \\
\text { returns distribution }\end{array}$} \\
\hline & & & EUROSTOXX SI & DJWSI & I EUROSTOXX & DJWSI \\
\hline 1 & Indexed & ONEOK & 0.63 & 0.63 & 0.622 & 0.54 \\
\hline 2 & Indexed & Dow Inc & 0.65 & 0.72 & 0.91 & 0.94 \\
\hline 3 & Indexed & Newmont Corporation & 0.38 & 0.37 & 0.43 & 0.55 \\
\hline 4 & Indexed & Sempra Energy & 0.61 & 0.72 & 0.82 & 0.65 \\
\hline 5 & Indexed & IMCD & 0.6 & 0.55 & 0.61 & 0.783 \\
\hline 6 & Indexed & UMICORE & 0.49 & 0.41 & 0.65 & 0.794 \\
\hline 7 & Indexed & STORA ENSO R & 0.719 & 0.61 & 0.42 & 0.553 \\
\hline 8 & Indexed & LINDE & 0.84 & 0.715 & 0.76 & 0.953 \\
\hline 9 & Indexed & AIR LIQUIDE & 0.839 & 0.744 & 0.71 & 0.924 \\
\hline 10 & Indexed & IBERDROLA & 0.727 & 0.66 & 0.57 & 0.766 \\
\hline 11 & Indexed & SAINT GOBAIN & 0.715 & 0.73 & 0.87 & 0.967 \\
\hline 12 & Indexed & RWE & 0.79 & 0.64 & 0.45 & 0.596 \\
\hline 13 & Indexed & SIGNIFY & 0.58 & 0.47 & 0.69 & 0.843 \\
\hline 14 & Indexed & ENEL & 0.762 & 0.66 & 0.54 & 0.707 \\
\hline 15 & Indexed & KINGSPAN GRP & 0.55 & 0.51 & 0.84 & 0.893 \\
\hline 16 & Indexed & BOUYGUES & 0.81 & 0.67 & 0.68 & 0.894 \\
\hline 17 & Indexed & COVESTRO & 0.757 & 0.48 & 0.96 & 0.844 \\
\hline 18 & Indexed & SNAM RETE GAS & 0.522 & 0.77 & 0.757 & 0.828 \\
\hline 19 & Indexed & $\mathrm{CRH}$ & 0.69 & 0.68 & 0.7 & 0.91 \\
\hline \multirow[t]{2}{*}{20} & Indexed & $\mathrm{A} 2 \mathrm{~A}$ & 0.77 & 0.75 & 0.73 & 0.533 \\
\hline & & & EUROSTOXX & DJI & EUROSTOXX & DJI \\
\hline 1 & Non-indexed & Exxon Mobil & 0.65 & 0.76 & 0.41 & 0.33 \\
\hline 2 & Non-indexed & Chevron & 0.67 & 0.81 & 0.66 & 0.55 \\
\hline 3 & Non-indexed & AES & 0.63 & 0.722 & 0.61 & 0.74 \\
\hline 4 & Non-indexed & $\begin{array}{l}\text { Diamondback Energy, } \\
\text { Inc }\end{array}$ & 0.51 & 0.54 & 0.51 & 0.45 \\
\hline 5 & Non-indexed & Exelon & 0.63 & 0.81 & 0.77 & 0.64 \\
\hline 6 & Non-indexed & VICTREX & 0.52 & 0.45 & 0.82 & 0.98 \\
\hline 7 & Non-indexed & SIKA & 0.62 & 0.52 & 0.41 & 0.58 \\
\hline 8 & Non-indexed & WEIR GRP & 0.51 & 0.53 & 0.66 & 0.79 \\
\hline 9 & Non-indexed & TOTAL & 0.68 & 0.6 & 0.7 & 0.58 \\
\hline 10 & Non-indexed & ENGIE & 0.67 & 0.57 & 0.96 & 0.87 \\
\hline 11 & Non-indexed & $\begin{array}{l}\text { SCOTTISH AND } \\
\text { SOUTHERN } \\
\text { ENERGY }\end{array}$ & 0.82 & 0.55 & 0.48 & 0.63 \\
\hline 12 & Non-indexed & EQUINOR & 0.77 & 0.76 & 0.81 & 0.69 \\
\hline 13 & Non-indexed & ARCELORMITTAL & 0.68 & 0.55 & 0.74 & 0.86 \\
\hline 14 & Non-indexed & BOLIDEN & 0.76 & 0.54 & 0.66 & 0.82 \\
\hline 15 & Non-indexed & NIBE INDUSTRIER & 0.72 & 0.55 & 0.77 & 0.27 \\
\hline 16 & Non-indexed & SKF & 0.68 & 0.56 & 0.25 & 0.74 \\
\hline
\end{tabular}


Table 2 (continued)

\begin{tabular}{lllllll}
\hline & & & EUROSTOXX & DJI & EUROSTOXX & DJI \\
\hline 17 & Non-indexed & EVRAZ & 0.69 & 0.49 & 0.58 & 0.75 \\
18 & Non-indexed & ARKEMA & 0.71 & 0.48 & 0.86 & 0.94 \\
19 & Non-indexed & ANTOFAGASTA PLC & 0.66 & 0.58 & 0.78 & 0.511 \\
20 & Non-indexed & BP & 0.76 & 0.59 & 0.38 & 0.246 \\
\hline
\end{tabular}

\section{References}

Ashraf, B. N. (2020). Stock markets' reaction to COVID-19: Cases or fatalities? Research in International Business and Finance, 54, 101249. https://doi.org/10.1016/j.ribaf.2020.101249

Auer, B. R. (2016). Do socially responsible investment policies add or destroy European stock portfolio value? Journal of Business Ethics, 135, 381-397.

Benson, K. L., \& Humphrey, J. E. (2008). Socially responsible investment funds: Investor reaction to current and past returns. Journal of Banking and Finance, 32, 1850-1859.

Bhattacharya, A., \& Kojima, S. (2012). Power sector investment risk and renewable energy: A Japanese case study using portfolio risk optimization method. Energy Policy, 40, 69-80.

Bigerna, S., Bollino, C. A., \& Polinori, P. (2021). Oil import portfolio risk and spillover volatility. Resources Policy, 70, 101976.

Birindelli, G., \& Chiappini, H. (2021). Climate change policies: Good news or bad news for firms in the European Union? Corporate Social Responsibility and Environmental Management, 28, 831-848.

Broadstock, D. C., Chan, K., Cheng, L. T. W., \& Wang, X. (2021). The role of ESG performance during times of financial crisis: Evidence from COVID-19 in China. Finance Research Letters, 38, 101716.

Caferra, R., \& Vidal-Tomás, D. (2021). Who raised from the abyss? A comparison between cryptocurrency and stock market dynamics during the COVID-19 pandemic. Finance Research Letters, 43, 101954.

Capelle-Blancard, G., \& Monjon, S. (2012). Trends in the literature on socially responsible investment: Looking for the keys under the lamppost. Business Ethics: A European Review, 21, 239-250.

Chiappini, H., Vento, G., \& De Palma, L. (2021). The impact of COVID-19 lockdowns on sustainable indexes. Sustainability, 13, 1846.

Clacher, I., \& Hagendorff, J. (2012). Do announcements about corporate social responsibility create or destroy shareholder wealth? Evidence from the UK. Journal of Business Ethics, 106, 253-266.

Collison, D. J., Cobb, G., Power, D. M., \& Stevenson, L. A. (2008). The financial performance of the FTSE4Good indices. Corporate Social Responsibility and Environmental Management, 15, 14-28.

Consolandi, C., Jaiswal-Dale, A., Poggiani, E., \& Vercelli, A. (2009). Global standards and ethical stock indexes: The case of the Dow Jones Sustainability Stoxx Index. Journal of Business Ethics, 87, 185-197.

da Carvalho, M. G. (2012). EU energy and climate change strategy. Energy, 40, 19-22.

de Cunha, F. A. F. S., de Oliveira, E. M., Orsato, R. J., Klotzle, M. C., Oliveira, F. L. C., \& Caiado, R. G. G. (2020). Can sustainable investments outperform traditional benchmarks? Evidence from global stock markets. Business Strategy and the Environment, 29, 682-697.

Döttling, R., \& Kim, S. (2020). Sustainability preferences under stress: Evidence from mutual fund flows during COVID-19, (May 5, 2021). Available at SSRN: https://ssrn.com/abstract=3656756 or https:// doi.org/10.2139/ssrn.3656756.

Endrikat, J. (2016). Market reactions to corporate environmental performance related events: A metaanalytic consolidation of the empirical evidence. Journal of Business Ethics, 138, 535-548.

Escrig-Olmedo, E., Fernández-Izquierdo, M. Á., Ferrero-Ferrero, I., Rivera-Lirio, J. M., \& Muñoz-Torres, M. J. (2019). Rating the raters: Evaluating how ESG rating agencies integrate sustainability principles. Sustainability, 11, 915. 
Folger-Laronde, Z., Pashang, S., Feor, L., \& ElAlfy, A. (2020). ESG ratings and financial performance of exchange-traded funds during the COVID-19 pandemic. Journal of Sustainable Finance and Investment. https://doi.org/10.1080/20430795.2020.1782814.

Gebka, B., \& Wohar, M. E. (2013). Causality between trading volume and returns: Evidence from quantile regressions. International Review of Economics and Finance, 27, 144-159.

Herskovic, B. (2018). Networks in production: Asset pricing implications. Journal of Finance, 73, 1785-1818.

Humphrey, J. E., Lee, D. D., \& Shen, Y. (2012). Does it cost to be sustainable? Journal of Corporate Finance, 18, 626-639.

Inclan, C., \& Tiao, G. C. (1994). Use of cumulative sums of squares for retrospective detection of changes of variance. Journal of American Statistical Association, 89, 913-923.

Lahcen, B., Brusselaers, J., Vrancken, K., Dams, Y., Paes, C. D. S., Eyckmans, J., \& Rousseau, S. (2020). Green recovery policies for the COVID-19 crisis: Modelling the impact on the economy and greenhouse gas emissions. Environmental and Resource Economics, 76, 731-750.

Lean, H. H., \& Pizzutilo, F. (2020). Performances and risk of socially responsible investments across regions during crisis. International Journal of Finance and Economics, 26, 3556-3568.

Leite, P., \& Cortez, M. C. (2014). Style and performance of international socially responsible funds in Europe. Research in International Business and Finance, 30, 248-267.

Leite, P., \& Cortez, M. C. (2015). Performance of European socially responsible funds during market crises: Evidence from France. International Review of Financial Analysis, 40, 132-141.

Luenberger, D. G. (1997). Investment science. OUP Cat.

Majapa, M., \& Gossel, S. J. (2016). Topology of the South African stock market network across the 2008 financial crisis. Physica a: Statistical Mechanics and Its Applications, 445, 35-47.

Managi, S., Okimoto, T., \& Matsuda, A. (2012). Do socially responsible investment indexes outperform conventional indexes? Applied Financial Economics, 22, 1511-1527.

Markowitz, H. (1952). Portfolio selection. Journal of Finance 7(1), 77-91.

Matallín-Sáez, J. C., Soler-Domínguez, A., \& Tortosa-Ausina, E. (2016). Does socially responsible mutual fund performance vary over the business cycle? New insights on the effect of idiosyncratic SR features. Business Ethics: A European Review, 28(1), 78-98.

Mukanjari, S., \& Sterner, T. (2020). Charting a "green path" for recovery from COVID-19. Environmental and Resource Economics, 76, 825-853.

Nofsinger, J., \& Varma, A. (2014). Socially responsible funds and market crises. Journal of Banking and Finance, 48, 180-193. https://doi.org/10.1016/j.jbankfin.2013.12.016

Qi, Y., \& Li, X. (2020). On imposing ESG constraints of portfolio selection for sustainable investment and comparing the efficient frontiers in the weight space. SAGE Open, 10, 2158244020975070.

Renneboog, L., Ter Horst, J., \& Zhang, C. (2008). Socially responsible investments: Institutional aspects, performance, and investor behavior. Journal of Banking and Finance, 32, 1723-1742. https://doi. org/10.1016/j.jbankfin.2007.12.039

Restrepo, N., Uribe, J. M., \& Manotas, D. (2018). Financial risk network architecture of energy firms. Applied Energy, 215, 630-642.

Revelli, C., \& Viviani, J. (2015). Financial performance of socially responsible investing (SRI): What have we learned? A meta-analysis. Business Ethics: A European Reviews, 24, 158-185.

Santos-Alamillos, F. J., Thomaidis, N. S., Usaola-García, J., Ruiz-Arias, J. A., \& Pozo-Vázquez, D. (2017). Exploring the mean-variance portfolio optimization approach for planning wind repowering actions in Spain. Renewable Energy, 106, 335-342.

Selmi, R., Hammoudeh, S., Errami, Y., \& Wohar, M. E. (2021). Is COVID-19 related anxiety an accelerator for responsible and sustainable investing? A sentiment analysis. Applied Economics, 53, $1528-1539$.

Sharpe, W. F. (1963). A simplified model for portfolio analysis. Management Science, 9, 277-293.

Smith, L. (2010). The green deal. Science and Environment Sector. House Commons Library.

Ur Rehman, R., Zhang, J., Uppal, J., Cullinan, C., \& Akram Naseem, M. (2016). Are environmental social governance equity indices a better choice for investors? An Asian perspective. Business Ethics: A European Review, 25, 440-459.

Vidal-Tomás, D. (2021). Transitions in the cryptocurrency market during the COVID-19 pandemic: A network analysis. Finance Research Letters, 101981

Wang, Y., Li, H., Guan, J., \& Liu, N. (2019). Similarities between stock price correlation networks and co-main product networks: Threshold scenarios. Physica a: Statistical Mechanics and Its Applications, 516, 66-77. 
Wu, J., Lodorfos, G., Dean, A., \& Gioulmpaxiotis, G. (2017). The market performance of socially responsible investment during periods of the economic cycle-Illustrated using the case of FTSE. Managerial and Decision Economics, 38, 238-251.

Yoshino, N., Taghizadeh-Hesary, F., \& Otsuka, M. (2021). COVID-19 and optimal portfolio selection for investment in sustainable development goals. Finance Research Letters, 38, 101695.

Zheng, B., Zhang, Y., \& Chen, Y. (2021). Asymmetric connectedness and dynamic spillovers between renewable energy and rare earth markets in China: Evidence from firms' high-frequency data. Resources Policy, 71, 101996.

Publisher's Note Springer Nature remains neutral with regard to jurisdictional claims in published maps and institutional affiliations.

\section{Authors and Affiliations}

\section{Rocco Caferra $^{1,2} \cdot$ Pasquale Marcello Falcone $^{3} \cdot$ Andrea Morone $^{1}$. Piergiuseppe Morone ${ }^{4}$ (D)}

1 Dipartimento di Economia, Management e Diritto dell'Impresa, Università degli Studi di Bari Aldo Moro, Bari, Italy

2 Universitat Jaume I, Department of Economics, Castellon de la Plana, Spain

3 Department of Business and Economics, University of Naples "Parthenope", Naples, Italy

4 Bioeconomy in Transition Research Group, UnitelmaSapienza, Viale Regina Elena, 295, 00161 Roma, Italy 